\title{
Heavy metals in fish and its association with autoimmunity in the development of juvenile idiopathic arthritis: a prospective birth cohort study
}

\author{
Erik Kindgren ${ }^{1,2,3^{*}}$ (D), Carlos Guerrero-Bosagna ${ }^{4}$ and Johnny Ludvigsson ${ }^{2,5}$
}

\begin{abstract}
Background: The etiology of Juvenile Idiopathic Arthritis (JIA) is poorly understood. The purpose of this study was to examine the possible influence of early nutrition on later development of JIA.

Methods: In a population-based prospective birth cohort of 15,740 children we collected nutritional data, including fish consumption, and biological samples during pregnancy, at birth and at different ages. 16 years after study inclusion we identified 42 children with JIA, of whom 11 were positive for Antinuclear Antibodies (ANA). Heavy metals were analysed in cord blood of all $42 \mathrm{JIA}$ patients and 40 age and sex-matched controls. A multivariable logistic regression model, adjusted for relevant factors, was used as well as Mann-Whitney U-test.

Results: Fish consumption more than once a week during pregnancy as well as during the child's first year of life was associated with an increased risk of JIA (aOR $4.5(1.95-10.4) ; p<0.001$ and aOR $5.1(2.1-12.4) p<0.001)$ and of ANApositivity (aOR 2.2 (1.4-3.6); $p=0.002$ and $p<0.001$ ). Concentrations of $\mathrm{Al}, \mathrm{Cd}, \mathrm{Hg}$ and $\mathrm{Li}$ in cord blood were significantly higher in the JIA-group than in controls. The ANA-positive, all of whom had consumed fish >once/week their first year, had significantly higher concentrations of $\mathrm{Al}(p<0.001), \mathrm{Cd}(p=0.003)$, and $\mathrm{Li}(p<0.001)$ in cord blood than controls. Frequency of fish consumption correlated with concentrations of $\mathrm{Cd}(p=0.003), \mathrm{Li}(p=0.015)$ and $\mathrm{Hg}(p=0.011)$.

Conclusions: Moderate exposure to heavy metals, associated with fish consumption, during pregnancy and early childhood may cause effects on the immune system of the offspring, resulting in ANA positivity and JIA.

Keywords: Juvenile idiopathic arthritis (IIA), Arthritis, Epidemiology, Autoimmunity, Nutrition, Fish, Aluminium, Cadmium, Lithium, Heavy metals, Rheumatic disease
\end{abstract}

\section{Introduction}

Juvenile idiopathic arthritis (JIA) is the most common chronic childhood rheumatic disease. It is a heterogeneous autoimmune disease comprising seven categories with onset before 16 years of age [1]. Antinuclear antibody (ANA) positivity can be found in all subtypes of JIA but is more frequent in patients with oligoarthritis and rheumatoid factor (RF) negative polyarthritis [2, 3]. The starting point of autoimmunity which leads to JIA and

\footnotetext{
* Correspondence: erik@kindgren.org

${ }^{1}$ Department of Pediatrics, Västervik Hospital, Västervik, Sweden

${ }^{2}$ Division of Pediatrics, Department of Clinical and Experimental Medicine,

Linköping University, Linköping, Sweden
}

Full list of author information is available at the end of the article
Rheumatoid Arthritis (RA) is still unknown. These autoimmune diseases are severe, even disabling, and incurable. Therefore, it is important to try to prevent their development, both for the patients themselves and for society.

We have performed a prospective study focusing on environmental factors during pregnancy and childhood in a general population. The aim is to explore environmental factors, such as early feeding, in relation to risk of later development of JIA. Breastfeeding seems to be associated with JIA, as described in a previous paper [4]. Increased knowledge of the role of early nutrition and its association with autoimmunity is of crucial importance, as dietary recommendations may help to prevent these chronic diseases.

(c) The Author(s). 2019 Open Access This article is distributed under the terms of the Creative Commons Attribution 4.0 International License (http://creativecommons.org/licenses/by/4.0/), which permits unrestricted use, distribution, and reproduction in any medium, provided you give appropriate credit to the original author(s) and the source, provide a link to the Creative Commons license, and indicate if changes were made. The Creative Commons Public Domain Dedication waiver (http://creativecommons.org/publicdomain/zero/1.0/) applies to the data made available in this article, unless otherwise stated. 


\section{Material and methods}

The Swedish National Patient Register, launched in 1964, is maintained by the Swedish National Board of Health and Welfare (http://www.socialstyrelsen.se/english). More than $99 \%$ of all somatic and psychiatric hospital discharges, as well as outpatient visits from both private and public caregivers, are recorded in this population-based register. Several items are recorded, including International Classification of Diseases (ICD) codes and the personal identity number (PIN - a unique 10-digit number assigned to all Swedish residents) [5].

The Swedish JIA-registry started in 2009. In 2014, there were 1700 patients included and coverage was almost complete. Through the unique PIN, information on each individual patient can be linked to other registers.

In Sweden, all children aged 0-18 years diagnosed with JIA or RA are treated at paediatric clinics in hospitals or at paediatric rheumatology clinics.

\section{Participants and design}

The current study was part of the All Babies in Southeast Sweden-project (ABIS), which aims to study causes of immune-mediated diseases by following a general population birth cohort though childhood and adolescence. All parents with children born between Oct 1st 1997 and Oct 1st 1999 in Southeast Sweden $(n=21,700)$ were asked to participate in the study. 17,055 (78.6\%) of the families gave their informed consent to participate. According to the ABIS-protocol the children were monitored by biological samples taken at birth and then at the ages $1,2.5,5,8,10-12$ and 13-16 years as well as questionnaires about life-style and environmental factors. A detailed diary was used for daily registration of certain facts related to nutrition and infections including the exact time (date) of introduction of different food items during the first year of life. The 1-year questionnaires were completed by 10,883 families, and in addition, diaries were collected for 9849 children. All subjects with missing values were excluded from the statistical model.

Every member of the ABIS-cohort was followed to see if they developed JIA by linking data from the ABIScohort and The Swedish National Patient Register [6] by using a unique 10-digit PIN [5]. We identified 59 children with an ICD code of JIA (ICD 9-10 code M08-09) and had accepted to participate in ABIS (see Fig. 1). Three of children had moved out of the ABIS region, but could be found and included with the PIN. 17/59 patients were excluded due to misdiagnosis (mostly monoarthritis that later proved to be reactive arthritis), after communication with the paediatric rheumatologists at local hospitals who reviewed the medical records of all 59 patients. Of the remaining 42, had 41 completed the questionnaire after delivery, and 32 of them had completed both the questionnaire after delivery and the 1 year follow up questionnaire. 29 of 32 had also completed the detailed nutrition diary during the child's first year. All cases of JIA and their categories were doublechecked via The Swedish paediatric JIA-registry. ANA

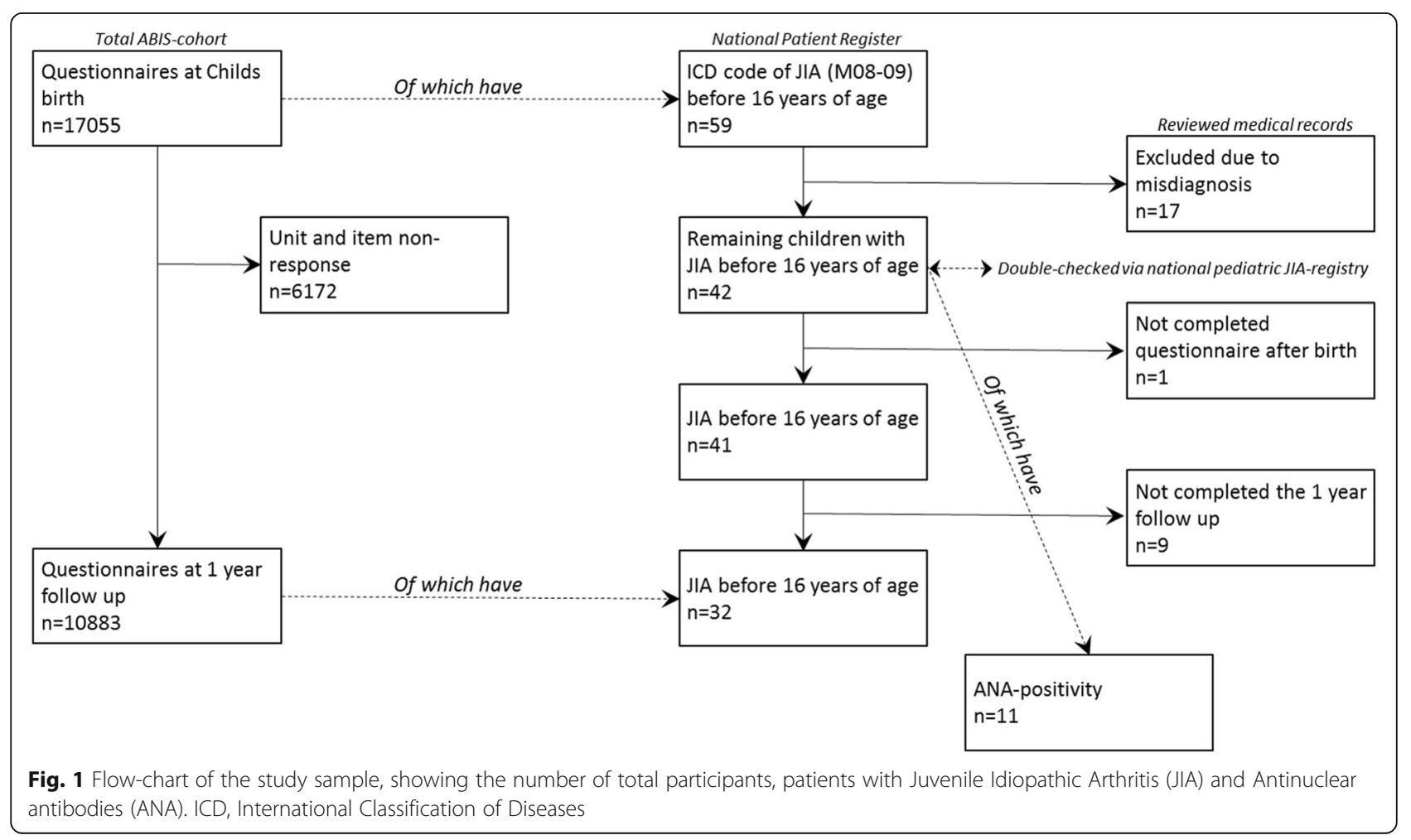


positivity was detected in 11 patients with JIA. Data on fish consumption were collected from both the detailed diary and the questionnaires. Heavy metals were analysed in all 42 JIA patients and in an additional 40 randomly selected age and sex-matched controls.

\section{Serology}

ANA positivity was detected using indirect immunofluorescence with human epithelioid cells (Hep-2 cells) as substrate [7]. ANA positivity was defined as at least two positive results (titer of $\geq 1: 160$ ) analysed at least 3 months apart. RF was determined by latex agglutination test.

\section{Cord blood analyses}

The analysis of heavy metals was performed by ALS Scandinavia $\mathrm{AB}$ (Luleå, Sweden) using the 'ultrasensitive inductively coupled plasma sector field mass spectrometry method' (ICP-SFMS) [8] after acid digestion with $\mathrm{HNO} 3$, according to the standards ISO 17294-1 (https://www.iso.org/standard/32957.html) and 2 (https://www.iso.org/standard/62962.html), and the EPA Method 200.8 (https://www.epa.gov/homeland-securityresearch/epa-method-2008-determination-trace-elementswaters-and-wastes). Heavy metals analysed were: Aluminium (Al), Cadmium (Cd), Mercury ( $\mathrm{Hg})$, Lithium (Li), Lead $(\mathrm{Pb})$, Zinc $(\mathrm{Zn})$, Copper $(\mathrm{Cu})$, Arsenic $(\mathrm{As})$, Magnesium $(\mathrm{Mg})$ and Iron $(\mathrm{Fe})$.

\section{Statistics}

Homogeneity of variance was tested using Levene's test and the normality for independent variables was revised both graphically and by the Shapiro-Wilk test.

Odds ratio (OR) with 95\% confidence intervals (95\% CIs) were estimated using (univariate) logistic regression. JIA and ANA positivity were used as the dependent variables. Amount of dietary fish intake and possible confounding factors (listed below) associated with incidence of JIA were analysed. Dietary fish intake was also dichotomized to either low intake $(<1$ per week) or moderate-high intake ( $\geq 1$ per week). At the time when ABIS was initiated, the Swedish National Institute of Public Health recommended dietary intake of fish $2-3$ times a week during pregnancy and 2-3 times a week during the first year of life. Variables with $p<0.1$ in the univariate analyses were included in the final multivariate logistic regression model as possible confounding factors associated with fish consumption.

Independent samples t-test and Mann-Whitney U-test, adjusted for confounding factors (listed below), was used to calculate differences in levels of heavy metals and fish consumption between the groups. All $P$-values are twotailed and a value below 0.05 and a 95\% CI not overlapping the null value 1.00 for the OR were considered as statistically significant.
Possible confounding factors included heredity for rheumatism (JIA or RA in first- and second-degree relatives), parity, mode of delivery, preterm birth, duration of (exclusive and total) breastfeeding, introduction of formula, parental age, education, smoking habits, and whether or not the parents were born outside Sweden.

Statistics were calculated using the Statistical Package for Social Science (SPSS 25.0 software; SPSS Inc., Chicago, IL, USA).

\section{Results \\ Cases}

Forty-one cases of JIA with complete questionnaires after delivery were identified. The number and proportion of patients in each JIA category are shown in Table 1 . The unclassified category based on the ILAR-criteria [1], either did not fulfil criteria for any category or they met categorization criteria for 2 subtypes. Family history of RA/JIA in first- and second-degree family member are presented in Table 1.

\section{Fish and JIA}

Fish consumption more than once a week during pregnancy was associated with an increased risk of JIA (aOR 4.5 (1.95-10.4); $p<0.001)$. The child's consumption of fish more than once a week during the first year of life was also associated with an increased risk of JIA (aOR $5.1(2.1-12.4) \mathrm{p}<0.001)$, as illustrated in Table 1 and Fig. 2. $87 \%(27 / 31)$ of children with JIA was exposed to fish more than once a week during pregnancy or during their first year, compared to $56 \%$ in the general population (aOR 5.4 (1.9-15.4) $p=0.002)$.

\section{Fish and ANA}

Fish consumption more than once a week during pregnancy as well as during the child's first year of life was associated with an increased risk of ANA-positivity (aOR 2.2 (1.4-3.6); $\mathrm{p}=0.002$ and $\mathrm{p}<0.001$, respectively). $100 \%$ of children with ANA-positivity had consumed fish more than once a week during their first year. Fish consumption at the age of 2.5 and 5 years showed no association with ANA-positivity (Table 1 and Fig. 2).

\section{Heavy metals and ANA}

Concentrations of $\mathrm{Al}, \mathrm{Cd}$ and $\mathrm{Li}$ in cord blood were significantly higher in the ANA-group than in controls (Table 2). $\mathrm{Chi}^{2}$-test with concentrations of heavy metals dichotomized below/above the detection level ( $\mathrm{Al} 5.00 \mu \mathrm{g} / \mathrm{l} ; \mathrm{Cd} 0.05 \mu \mathrm{g} / \mathrm{l}$; Li $1.00 \mu \mathrm{g} / \mathrm{l})$ showed significant results for $\mathrm{Al}(p=0.040)$, $\mathrm{Cd}(p=0.008)$ and $\mathrm{Li}(p=0.006) .82 \%$ of the children with ANA antibodies had concentrations of $\mathrm{Al}, \mathrm{Cd}$, or Li higher than the mean, and $64 \%$ had concentrations two standard deviations above the mean. 91\% (10/11) of the ANApositive had elevated concentrations higher than the mean of one or more of all the analysed heavy metals. 
Table 1 Risk of Juvenile Idiopathic Arthritis (JIA) and Antinuclear antibodies (ANA) according to dietary fish intake and family history. $\mathrm{OR}$ and $p$-values from logistic regression. Classification according to ILAR criteria. The number and proportion of patients in each category

\begin{tabular}{|c|c|c|c|c|c|c|c|}
\hline & \multirow[t]{3}{*}{ Controls } & \multicolumn{3}{|l|}{$J \mathrm{~A}$} & \multicolumn{3}{|l|}{ ANA+ } \\
\hline & & \multicolumn{6}{|c|}{ 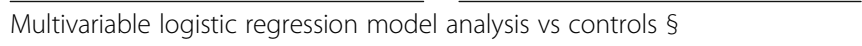 } \\
\hline & & & $\mathrm{aOR}(95 \% \mathrm{Cl})$ & $p$ & & $\mathrm{aOR}(95 \% \mathrm{Cl})$ & $p$ \\
\hline Fish more than once a week during pregnancy & $(n=15,730)$ & $(n=41)$ & & & $(n=10)$ & & \\
\hline All fish & $4764(31 \%)$ & $19(46 \%)$ & $4.5(1.9-10.4)$ & $<0.001$ & $6(60 \%)$ & $2.2(1.4-3.6)$ & 0.002 \\
\hline Fish from Baltic Sea & $791(6 \%)$ & $4(10 \%)$ & $2.3(1.1-5.0)$ & 0.034 & $3(30 \%)$ & $7.6(1,9-30.2)$ & 0.001 \\
\hline Fish from lake & $255(2 \%)$ & $0(0 \%)$ & 0 & 0.74 & $0(0 \%)$ & 0 & 1.000 \\
\hline Other fish & $4042(26 \%)$ & $17(42 \%)$ & $2.6(1.3-5.1)$ & 0.009 & $5(50 \%)$ & $5.5(0.8-14,7)$ & 0.085 \\
\hline Fish more than once a week during the baby's first year & $(n=10,473)$ & $(n=31)$ & & & $(n=8)$ & & \\
\hline All fish & $4547(43 \%)$ & $24(77 \%)$ & $5.1(2.1-12.4)$ & $<0.001$ & $8(100 \%)$ & * & 0.001 \\
\hline Fish from Baltic Sea & $1582(15 \%)$ & $9(29 \%)$ & $2.3(1.1-5.1)$ & 0.035 & $4(50 \%)$ & $5.6(1.4-22.6)$ & 0.014 \\
\hline Fish from lake & $458(4 \%)$ & $1(3 \%)$ & $0.7(0.097-5.2)$ & 0.74 & $0(0 \%)$ & 0 & 1.000 \\
\hline Other fish & $3387(32 \%)$ & $17(55 \%)$ & $2.9(1.4-5.9)$ & 0.005 & $5(63 \%)$ & $1.7(1.1-2.7)$ & 0.016 \\
\hline \multicolumn{8}{|l|}{ Family history / Heredity for JIA/RA } \\
\hline Mother with RA (n) & $157(1 \%)$ & $1(2 \%)$ & $2.5(0.3-18.5)$ & 0.362 & & & \\
\hline Father with RA (n) & $64(0 \%)$ & $0(0 \%)$ & 0 & 1.000 & & & \\
\hline Siblings with JIA/RA (n) & $48(0 \%)$ & $0(0 \%)$ & 0 & 1.000 & & & \\
\hline 2nd degree family member with RA (n) & $1431(9 \%)$ & $8(20 \%)$ & $1.3(1.0-1.5)$ & 0.022 & & & \\
\hline \multicolumn{8}{|l|}{ Category at Onset (ILAR) (n) } \\
\hline Oligoarticulart & & $19(46 \%)$ & & & & & \\
\hline Polyarticularł & & $5(12 \%)$ & & & & & \\
\hline Enthesitis-related arthritis & & $4(10 \%)$ & & & & & \\
\hline Psoriatic arthritis & & $4(10 \%)$ & & & & & \\
\hline Systemic & & $5(12 \%)$ & & & & & \\
\hline Unclassifiable & & $4(10 \%)$ & & & & & \\
\hline
\end{tabular}

Sheredity for rheumatism (JIA or RA in first- and second-degree relatives), parity, mode of delivery, preterm birth, duration of (exclusive and total) breastfeeding introduction of formula, mother's civil status, parental age, education, smoking habits, and whether or not the parents were born outside Sweden *Logistic regression not possible. $P$-value from Chi-square, statistically significant $p$-values and OR in bold

tPatients with oligoarticular disease, not possible to classify as extended or persistent because of missing data

$\ddagger$ Patients with polyarticular disease, not possible to classify as RF positive or negative because of missing data

\section{Heavy metals and JIA}

Concentrations of $\mathrm{Al}, \mathrm{Cd}, \mathrm{Hg}$ and $\mathrm{Li}$ in cord blood were significantly higher in the JIA-group than in controls (Table 2). $\mathrm{Chi}^{2}$-test of heavy metals dichotomized below/ above the detection level (Al $5.00 \mu \mathrm{g} / \mathrm{l} ; \mathrm{Cd} 0.05 \mu \mathrm{g} / \mathrm{l}$; $\mathrm{Hg} 0.200 \mu \mathrm{g} / \mathrm{l} ; \mathrm{Li} 1.00 \mu \mathrm{g} / \mathrm{l})$ showed significant results for $\mathrm{Al}(p<0.001), \mathrm{Cd}(p<0.001), \mathrm{Hg}(p<0.001)$ and Li $(p<0.001) .71 \%$ of the children with JIA had concentrations of $\mathrm{Al}, \mathrm{Cd}, \mathrm{Hg}$ or $\mathrm{Li}$ higher than the mean, and $52 \%$ had concentrations two standard deviations above the mean. 95\% (40/42) in the JIA-group had elevated concentrations higher than the mean of one or more of all the analysed heavy metals.

\section{Heavy metals and fish}

Frequency of (total) fish consumption during pregnancy correlated with concentrations of Cd ( $p=0.003), \mathrm{Li}(p=$
0.015) and $\mathrm{Hg}(p=0.011)$ in cord blood, but not with concentrations of $\mathrm{Al}(p=0.261)$ (Table 2). Consumption of fish from the Baltic Sea correlated with concentrations of $\mathrm{Cd}(\mathrm{p}=0.011)$, and consumption of "other fish" (defined as all sorts of fish except fish from the Baltic Sea and fresh water) correlated with concentrations of $\mathrm{Cd}(p=0.028)$, Li $(p=0.006)$ and $\mathrm{Hg}(p=0.012)$. Frequency of consumption of fish from fresh water was extremely low during pregnancy, as shown in Table 1. All statistical associations remained statistically significant when potential confounders (described in Material and methods section) were included in the model.

\section{Discussion}

In a population-based prospective birth cohort survey, we found that consumption of fish during pregnancy and the child's first year of life was associated with an 


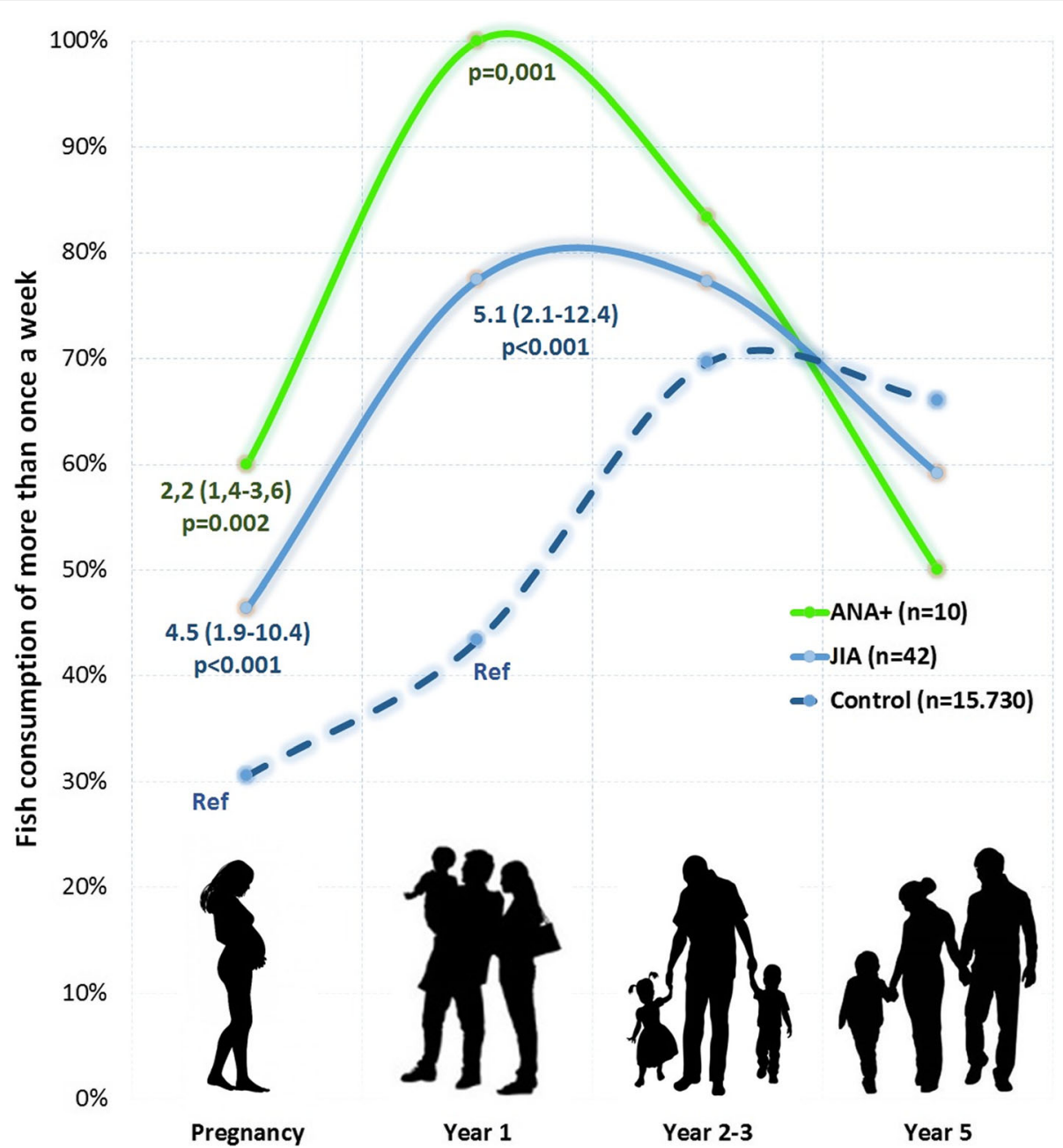

Fig. 2 Fish consumption of more than once a week during pregnancy as well as during the child's first years of life. Odds Ratio and p-value from Logistic regression

increased risk of ANA-positivity and JIA. Concentrations of $\mathrm{Cd}, \mathrm{Hg}$ and $\mathrm{Li}$ in cord blood correlated with the amount of fish the pregnant woman had eaten. Concentrations of $\mathrm{Al}, \mathrm{Cd}, \mathrm{Hg}$ and $\mathrm{Li}$ in cord blood were also significantly higher in the JIA-group than in controls. The ANA-positive, all of whom had consumed fish >once/ week their first year, had significantly higher concentrations of $\mathrm{Al}, \mathrm{Cd}$ and $\mathrm{Li}$ in cord blood than controls.

It could be hypothesized that eating fish may reduce the risk of inflammatory diseases because it is a major source of long-chain polyunsaturated fatty acids (PUFAs), especially $n-3$ PUFAs and micronutrients that may have anti-inflammatory properties and may modulate immune responses [9-11]. Gestational exposure to n-3 PUFAs is well known to have beneficial effects on children's subsequent health [12] On the other hand, fish is contaminated by marine pollutants, mainly PCBs, dioxins and other polychlorinated compounds, and heavy metals $[13,14]$. The positive effect of these PUFAs may therefore in part counterbalance the toxic impact of contaminants.

Murphy et al. have suggested that cadmium inhalation could be a plausible trigger for RA [13]. Smoking is highly associated with RA $[12,14]$. Cigarette smoke is an important environmental cause of elevated cadmium levels in humans [14]. Smokers have been observed to have blood cadmium concentrations twice as high as nonsmokers [9]. Moreover, increased cadmium exposure has been reported in non-smoking men with RA [10]. Hair cadmium levels are 3-fold higher in RA patients with occupational exposure to cadmium, irrespective of smoking history [15]. Patients with RA are more likely to have a profession associated with exposure to cadmium [14]. In addition, cadmium has been detected in the synovial fluid of patients with RA [16].

The main source of cadmium exposure in non-smokers is the diet [17]. Intestinal absorption of dietary cadmium is increased in individuals with low iron stores, and 
Table 2 Concentrations of heavy metals in cord blood. P-values, versus controls, from independent samples t-test and MannWhitney U-test. Dietary fish intake during pregnancy, dichotomized to either low intake ( $<1$ per week) or moderate-high intake $(\geq 1$ per week). P-values from independent samples t-test

\begin{tabular}{|c|c|c|c|c|c|c|c|c|}
\hline & \multirow[b]{2}{*}{$\begin{array}{l}\text { Controls } \\
(n=40)\end{array}$} & \multirow[b]{2}{*}{$\begin{array}{l}\text { JA } \\
(n=42)\end{array}$} & \multirow[b]{2}{*}{$p$} & \multirow[b]{2}{*}{$\begin{array}{l}\text { ANA+ } \\
(n=11)\end{array}$} & \multirow[b]{2}{*}{$p$} & \multicolumn{2}{|c|}{ Fish consumption } & \multirow[b]{2}{*}{$p$} \\
\hline & & & & & & $\begin{array}{l}<1 \text { per week } \\
(n=49)\end{array}$ & $\begin{array}{l}\geq 1 \text { per week } \\
(n=30)\end{array}$ & \\
\hline \multicolumn{9}{|l|}{ Aluminium, $\mathrm{Al}(\mu \mathrm{g} / \mathrm{L})$} \\
\hline Mean (SD) & $6.1(4.8)$ & $11.2(9.7)$ & $<0.001$ & $15.4(12.9)$ & $<0.001$ & $8.1(7.3)$ & $10.1(9.6)$ & 0.261 \\
\hline Median (Range) & $5.0(5.0-34.0)$ & $7.0(5.0-47.2)$ & & $12.1(5.0-47.2)$ & & $6.0(5.0-41.4)$ & $7.0(5.0-47.2)$ & \\
\hline \multicolumn{9}{|l|}{ Cadmium, $\mathrm{Cd}(\mu \mathrm{g} / \mathrm{L})$} \\
\hline Mean (SD) & $0.07(0.08)$ & $0.19(0.50)$ & $<0.001$ & $0.18(0.30)$ & $<0.001$ & $0.11(0.19)$ & $0.16(0.45)$ & 0.003 \\
\hline Median (Range) & $0.05(0.05-0.47)$ & $0.07(0.05-3.12)$ & & $0.08(0.05-1.08)$ & & $0.07(0.05-1.08)$ & $0.07(0.05-3.12)$ & \\
\hline \multicolumn{9}{|l|}{ Mercury, $\mathrm{Hg}(\mu \mathrm{g} / \mathrm{L})$} \\
\hline Mean (SD) & $0.24(0.08)$ & $0.33(0.14)$ & $<0.001$ & $0.33(0.17)$ & 0.067 & $0.28(0.13)$ & $0.31(0.11)$ & 0.011 \\
\hline Median (Range) & $0.20(0.20-0.53)$ & $0.30(0.20-1.01)$ & & $0.29(0.20-0.65)$ & & $0.21(0.20-1.01)$ & $0.30(0.20-0.65)$ & \\
\hline \multicolumn{9}{|l|}{ Lithium, Li ( $\mu \mathrm{g} / \mathrm{L})$} \\
\hline Mean (SD) & $1.01(0.04)$ & $2.79(6.03)$ & $<0.001$ & $6.21(11.41)$ & $<0.001$ & $1.31(0.70)$ & $3.01(7.14)$ & 0.015 \\
\hline Median (Range) & $1.00(1.00-1.22)$ & $1.00(1.00-39.40)$ & & $2.08(1.00-39.40)$ & & $1.00(1.00-4.14)$ & $1.00(1.00-39.40)$ & \\
\hline \multicolumn{9}{|l|}{ Lead, Pb ( $\mu \mathrm{g} / \mathrm{L})$} \\
\hline Mean (SD) & $0.64(0.50)$ & $0.52(0.06)$ & 0.902 & $0.53(0.08)$ & 0.952 & $0.58(0.44)$ & $0.56(0.18)$ & 0.790 \\
\hline Median (Range) & $0.5(0.5-3.5)$ & $0.5(0.5-0.8)$ & & $0.5(0.5-0.8)$ & & $0.5(0.5-3.5)$ & $0.5(0.5-1.3)$ & \\
\hline \multicolumn{9}{|l|}{ Zinc, Zn ( $\mu \mathrm{g} / \mathrm{L})$} \\
\hline Mean (SD) & $1070(521)$ & $1039(256)$ & 0.412 & $1184(375)$ & 0.216 & $1061(418)$ & $1062(404)$ & 0.998 \\
\hline Median (Range) & $966(683-3600)$ & $984(665-1780)$ & & $1030(707-1780)$ & & $996(683-3600)$ & $960(665-1062)$ & \\
\hline \multicolumn{9}{|l|}{ Copper, Cu ( $\mu \mathrm{g} / \mathrm{L})$} \\
\hline Mean (SD) & $417(106)$ & $509(281)$ & 0.516 & $490(171)$ & 0.291 & 473 (239) & $512(286)$ & 0.997 \\
\hline Median (Range) & $408(257-579)$ & $432(233-1540)$ & & $425(291-866)$ & & $424(233-1460)$ & 489 (259-1540) & \\
\hline \multicolumn{9}{|l|}{ Arsenic, As ( $\mu \mathrm{g} / \mathrm{L})$} \\
\hline Mean (SD) & $1.09(0.27)$ & $2.04(1.96)$ & 0.053 & $1.45(0.95)$ & 0.112 & $1.88(1.77)$ & $1.86(1.90)$ & 0.957 \\
\hline Median (Range) & $1.0(1.0-1.9)$ & $1.0(1.0-9.3)$ & & $1.0(1.0-4.2)$ & & $1.0(1.0-9.3)$ & $1.0(1.0-7.9)$ & \\
\hline \multicolumn{9}{|c|}{ Magnesium, Mg (mg/L) } \\
\hline Mean (SD) & $16.6(1.9)$ & $16.9(2.6)$ & 0.780 & $17.0(4.0)$ & 0.944 & $16.6(1.9)$ & $17.4(2.7)$ & 0.223 \\
\hline Median (Range) & $16.7(12.7-19.4)$ & $16.8(10.5-26.4)$ & & $16.7(10.5-26.4)$ & & $16.7(12.3-19.8)$ & $17.3(12.6-26.4)$ & \\
\hline \multicolumn{9}{|l|}{ Iron, Fe (mg/L) } \\
\hline Mean (SD) & $2.97(1.70)$ & $2.44(1.58)$ & 0.450 & $2.65(2.76)$ & 0.275 & $2.67(1.30)$ & $2.43(1.94)$ & 0.598 \\
\hline Median (Range) & $2.2(1.6-6.7)$ & $2.1(0.0-10.4)$ & & $1.8(0.0-10.4)$ & & $2.2(1.2-6.7)$ & $2.0(0-10.4)$ & \\
\hline
\end{tabular}

Statistically significant $p$-values in bold

significantly higher levels of cadmium could be found in women of reproductive age than in age-matched men [18]. Iron and cadmium compete with one another for transport into the intestinal mucosal cells. Since in pregnancy, the absorption of micronutrients increases, cadmium absorption is also increased [19, 20]. Generally, cadmium concentration in fish was higher in samples taken on the Baltic coast (Baltic Sea) compared to samples from the Swedish west coast [21]. Cadmium in low concentrations has been associated with a pro-inflammatory state [22], and high-dose cadmium given to rats has been shown to intensify disease activity of collagen-induced arthritis and expression of cytokines [23]. Several other studies have showed that cadmium is not only toxic to living organisms, but may also acts as an immunomodulator [24-26].

Humans do not have an effective elimination pathway for cadmium, and as a consequence the half-life of cadmium in the body is estimated to be $15-20$ years [27]. Massive cadmium accumulation in the body often leads to conditions such as respiratory disease, kidney failure, neurological disorders, and occasionally death [28]. 
Pharmacokinetic studies have shown that cadmium does not easily reach the foetus, but it accumulates in the placenta in high concentrations $[29,30]$. Although there is evidence that adult exposure to cadmium causes changes in the immune system, there are few reports of immunomodulatory effects of prenatal exposure to cadmium. Hanson et al. suggest that even very low levels of cadmium exposure during pregnancy can result in long term detrimental immunomodulatory effects in mouse offspring [30].

Aluminium is a potent stimulator of the immune system, which is the very reason it is used as an adjuvant [31]. In the absence of $\mathrm{Al}$ most vaccinations fail to launch an adequate immune response [31, 32]. Pro-inflammatory cytokines, such as interleukin- 1 and interleukin- 6 , are needed for adequate stimulation of antibody-producing B-cells. These cytokines are induced by $\mathrm{Al}$ adjuvants in vaccines [33]. Or results showed that cord blood aluminium does not correlate with fish consumption, but correlate with development of JIA. We have no explanation for this results. One can speculate about the source of the aluminium that leads to higher cord blood levels of Aluminium in JIA patients. Certain families may have been cooking in aluminium containers more often than other families. Another source could be intake of aluminium from foods (other than fish) or consumed by using aluminium-containing pharmaceuticals.

Mercury-induced autoimmunity in mice is an established model to study the mechanisms of the development of ANA. Immunotoxic effects, including ANA-positivity, have been clearly demonstrated in murine models in response to both organic and inorganic mercury [34]. In humans, occupational mercury exposure (as a result of small-scale gold mining) has been associated with elevated serum titers of ANA [11]. Methylmercury, at low levels generally considered safe, was associated with increased risk of high-titer ANA positivity among reproductive-age females in the general U.S. population [35].

Inorganic mercury contaminates waterways, can be biotransformed to methylmercury, and bioaccumulate in fish. Consumption of methylmercury-laden fish represents the most common route of exposure for humans [36]. Generally, mercury concentrations in fish living in the Baltic Sea are above the suggested target level for concentrations for the protection of predators against secondary poisoning of $20 \mathrm{ng} / \mathrm{g}$ wet weight [21].

Lithium therapy has been acknowledged to induce thyroid autoimmunity. Studies have reported a high prevalence of antithyroid antibodies in patients with affective disorders receiving lithium [37, 38]. Moreover, older studies have shown an increase in ANApositivity amongst patients with affective disorders on lithium therapy [39-41].

Thus, it is reasonable to believe that the increased concentrations of both cadmium, aluminium, mercury and lithium may play a role in changes in the immune balance, which could contribute to the development of autoimmune rheumatic diseases.

\section{Strengths and limitations of the study}

The small patient sample is a weakness due to the nature of the study, i.e. a birth cohort of a relatively rare disease. Different categories of JIA should be studied as separate groups $[42,43]$, but our study sample was too small to allow subgroup analysis. Although there were dropouts, these were not found to associate with heredity or subsequent diagnosis; therefore, it seems unlikely that our findings are a result of skewed attrition due to lost to followup participants. Other possible limitations are unmeasured contaminants in the fish, which may be associated with heavy metals, and leading to these observations, as well as unmeasured confounders, misclassification of diagnosis, selection bias and generalizability of the data.

Our study has some notable strengths. First, the prospective study design avoids the potential recall and selection biases of retrospective studies that collect data on nutrition and lifestyle after the diagnosis. The prospective design distributes any possible measurement biases equally between the JIA cases and non-cases, and recall bias is not likely to explain our findings. The ABIS cohort has been found to be representative for the Swedish general population in aspects such as education level [44]. Second, all cases of JIA were collected through the unique 10-digit PIN with codes from the Swedish National Patient Register with more than $99 \%$ coverage of all visits from both private and public caregivers. Subsequently, all cases were confirmed. This is a significant advantage over studies that rely only on self-report. Third, we have validated all diagnoses via The Swedish paediatric JIA-register and with the local physicians/hospitals. Fourth, the access to detailed information on important early life factors allowed us to control for several potential confounding factors that may have influenced our observed associations.

\section{Conclusions}

In conclusion, our results indicate that consumption of fish during pregnancy and first year of life may be a risk factor for development of JIA. Heavy metals could trigger autoimmunity leading to JIA, but further studies are needed to explore the possible causal link between heavy metal diet in early life (included pregnancy) and development of JIA. Our findings suggest that even moderate exposure to aluminium, cadmium, mercury and lithium during pregnancy and early childhood may cause effects on the immune system of the offspring, resulting in ANA positivity and JIA. Exposure to heavy metals during pregnancy and early childhood should be limited, and heavy metal content should be considered for inclusion in future guidelines for food and nutrition during pregnancy and infancy. More knowledge 
of the role of the child's early nutrition and its association to autoimmunity is of importance, as future guidelines for food and nutrition during pregnancy and infancy may help to prevent this chronic disease.

\section{Abbreviations \\ ABIS: All Babies in Southeast Sweden; Al: Aluminium; aOR: Adjusted odds ratio; As: Arsenic; Cd: Cadmium; Cl: Confidence Interval; Cu: Copper; Fe: Iron; Hg: Mercury; ICD: International Classification of Diseases; ILAR: International League of Associations for Rheumatology; JCA: Juvenile Chronic Arthritis; JIA: Juvenile Idiopathic Arthritis; JRA: Juvenile Rheumatoid Arthritis; Li: Lithium; Mg: Magnesium; OR: Odds Ratio; Pb: Lead; PIN: Personal Identification Number; RA: Rheumatoid Arthritis; RF: Rheumatoid Factor; RR: Relative risk; Zn: Zinc}

\section{Acknowledgements}

The authors would like to thank all the families taking part in the ABIS study and to the staff members of the Child Health Services in the region where questionnaires were collected and biological samples taken. Furthermore, special thanks to the following colleagues for their participation: Ingela Danielsson (Linköping); Nils-Åke Nilsson (Motala); Per Lewander (Norrköping); Maria Ekelund and Sven Johansson (Jönköping); Johan Jonsson (Växjö) and Sofia Hellerfelt (Karlskrona). We are also grateful to biostatistician Salmir Nasic for help with statistics, and to the Board of registry of the Swedish paediatric JIA-registry.

\section{Financial disclosure}

The authors have no financial relationships relevant to this article to disclose.

\section{Authors' contributions}

Dr. Kindgren was responsible of the collection of JIA-patients, statistical analyses, figures, data interpretation and the writing of the manuscript. Dr. Guerrero-Bosagna was responsible for cord blood analyses and review of the manuscript. Prof Ludvigsson was the principal investigator in the ABIS study, constructed questionnaires, collected all data and revised the paper. All authors read and approved the final manuscript.

\section{Funding}

This study as a part of the ABIS project was supported by the Swedish Child Diabetes Foundation (Barndiabetesfonden), the Juvenile Diabetes Research Foundation and the Medical Research Council of Southeast Sweden (FORSS). EK was supported by The Research Unit of Kalmar County Council, The Research Fund at Skaraborgs Hospital, Skaraborg Research and Development Council, Swedish Rheumatism Association and the Jerring Foundation. CGB appreciates funding from grant by the Escher Fund for Autism, as well as by the ERC 'GeneWell' grant. The funders had no role in study design, data collection and analysis, decision to publish, or preparation of the manuscript.

\section{Availability of data and materials}

The datasets used and analysed during the current study are available from the corresponding author on request.

\section{Ethics approval and consent to participate}

The ABIS study has been approved by the Research Ethics Committees of the Faculty of Health Sciences, Linköping University (Dnr 99227, Dnr 99321) and the Medical Faculty, Lund University (Dnr LU $83 \pm 97$ ). All parents or guardians gave their informed consent to participate also on behalf of their children.

\section{Consent for publication}

Not applicable.

\section{Competing interests}

The authors declare that they have no competing interests.

\section{Author details}

${ }^{1}$ Department of Pediatrics, Västervik Hospital, Västervik, Sweden. ${ }^{2}$ Division of Pediatrics, Department of Clinical and Experimental Medicine, Linköping University, Linköping, Sweden. ${ }^{3}$ Department of Pediatrics, Skaraborg Hospital, SE-541 85 Skövde, Skövde, Sweden. ${ }^{4}$ Avian Behavioural Genomics and Physiology Group, IFM Biology, Linköping University, Linköping, Sweden.
${ }^{5}$ Crown Princess Victoria Children's Hospital, Region Östergötland, Linköping, Sweden.

Received: 4 June 2019 Accepted: 20 June 2019

Published online: 02 July 2019

\section{References}

1. Petty RE, Southwood TR, Manners P, Baum J, Glass DN, Goldenberg J, He X, Maldonado-Cocco J, Orozco-Alcala J, Prieur AM, et al. International league of associations for rheumatology classification of juvenile idiopathic arthritis: second revision, Edmonton, 2001. J Rheumatol. 2004;31(2):390-2.

2. Guillaume S, Prieur AM, Coste J, Job-Deslandre C. Long-term outcome and prognosis in oligoarticular-onset juvenile idiopathic arthritis. Arthritis Rheum. 2000;43(8):1858-65.

3. Al-Matar MJ, Petty RE, Tucker LB, Malleson PN, Schroeder ML, Cabral DA. The early pattern of joint involvement predicts disease progression in children with oligoarticular (pauciarticular) juvenile rheumatoid arthritis. Arthritis Rheum. 2002:46(10):2708-15.

4. Kindgren E, Fredrikson M, Ludvigsson J. Early feeding and risk of juvenile idiopathic arthritis: a case control study in a prospective birth cohort. Pediatr rheumatol Online J. 2017;15(1):46.

5. Lunde AS, Lundeborg S, Lettenstrom GS, Thygesen L, Huebner J. The person-number systems of Sweden, Norway, Denmark, and Israel. In: Vital and health statistics Series 2, Data evaluation and methods research, vol. 84; 1980. p. 1-59.

6. Sverige. Socialstyrelsen: Kvalitet och innehåll i patientregistret : utskrivningar från slutenvård 1964-2006 och besök i öppenvård (exklusive primärvårdsbesök) 1997-2006. Stockholm: Socialstyrelsen; 2008.

7. Osborn TG, Patel NJ, Moore TI, Zuckner J. Use of the HEp-2 cell substrate in the detection of antinuclear antibodies in juvenile rheumatoid arthritis. Arthritis Rheum. 1984:27(11):1286-9.

8. Planchon FAM, Boutron CF, Barbante C, Wolff EW, Cozzi G, Gaspari V, Ferrari $C P$, Cescon P. Ultrasensitive determination of heavy metals at the subpicogram per gram level in ultraclean Antarctic snow samples by inductively coupled plasma sector field mass spectrometry. Anal Chim Acta. 2001;450(1-2):193-205

9. Bernhard D, Rossmann A, Wick G. Metals in cigarette smoke. IUBMB Life. 2005:57(12):805-9.

10. Afridi HI, Kazi TG, Brabazon D, Naher S. Association between essential trace and toxic elements in scalp hair samples of smokers rheumatoid arthritis subjects. Sci Total Environ. 2011;412-413:93-100.

11. Gardner RM, Nyland JF, Silva IA, Ventura AM, de Souza JM, Silbergeld EK. Mercury exposure, serum antinuclear/antinucleolar antibodies, and serum cytokine levels in mining populations in Amazonian Brazil: a cross-sectional study. Environ Res. 2010;110(4):345-54.

12. Di Giuseppe D, Discacciati A, Orsini N, Wolk A. Cigarette smoking and risk of rheumatoid arthritis: a dose-response meta-analysis. Arthritis Res Ther. 2014; 16(2):R61.

13. Murphy D, James B, Hutchinson D. Could the significantly increased risk of rheumatoid arthritis reported in Italian male steel workers be explained by occupational exposure to cadmium? J Occup Med Toxicol. 2016;11:21.

14. Hutchinson D. Cadmium, one of the villains behind the curtain: has exposure to cadmium helped to pull the strings of seropositive rheumatoid arthritis pathogenesis all along? Int J Rheum Dis. 2015;18(5):570-3 quiz 574-576.

15. Afridi HI, Kazi TG, Brabazon D, Naher S. Interaction between zinc, cadmium, and lead in scalp hair samples of Pakistani and Irish smokers rheumatoid arthritis subjects in relation to controls. Biol Trace Elem Res. 2012;148(2):139-47.

16. Pedersen LM, Christensen JM. Chromium, nickel and cadmium in biological fluids in patients with rheumatoid arthritis compared to healthy controls. Acta Pharmacol Toxicol. 1986;59 Suppl 7:392-5.

17. Ferrari $P$, Arcella D, Heraud F, Cappe S, Fabiansson S. Impact of refining the assessment of dietary exposure to cadmium in the European adult population. Food Addit Contam Part A Chem Anal Control, Expo Risk Assess. 2013:30(4):687-97.

18. Lee BK, Kim Y. Sex-specific profiles of blood metal levels associated with metal-Iron interactions. Saf Health Work. 2014;5(3):113-7.

19. Akesson A, Berglund M, Schutz A, Bjellerup P, Bremme K, Vahter M. Cadmium exposure in pregnancy and lactation in relation to iron status. Am J Public Health. 2002;92(2):284-7.

20. Vahter M, Akesson A, Liden C, Ceccatelli S, Berglund M. Gender differences in the disposition and toxicity of metals. Environ Res. 2007;104(1):85-95. 
21. Bignert ADS, Faxneld S, Nyberg E. Comments Concerning the National Swedish Contaminant Monitoring Programme in Marine Biota; 2017. p. 2017.

22. Olszowski T, Baranowska-Bosiacka I, Gutowska I, Chlubek D. Proinflammatory properties of cadmium. Acta Biochim Pol. 2012;59(4):475-82.

23. Ansari MM, Neha KHA. Effect of cadmium chloride exposure during the induction of collagen induced arthritis. Chem Biol Interact. 2015;238:55-65.

24. Pillet S, D'Elia M, Bernier J, Bouquegneau JM, Fournier M, Cyr DG. Immunomodulatory effects of estradiol and cadmium in adult female rats. Toxicol Sci. 2006;92(2):423-32.

25. Krocova Z, Macela A, Kroca M, Hernychova L. The immunomodulatory effect(s) of lead and cadmium on the cells of immune system in vitro. Toxicol In Vitro. 2000;14(1):33-40.

26. Leffel EK, Wolf C, Poklis A, White KL Jr. Drinking water exposure to cadmium, an environmental contaminant, results in the exacerbation of autoimmune disease in the murine model. Toxicology. 2003;188(2-3):233-50.

27. Jin T, Lu J, Nordberg M. Toxicokinetics and biochemistry of cadmium with special emphasis on the role of metallothionein. Neurotoxicology. 1998; 19(4-5):529-35.

28. Waalkes MP, Coogan TP, Barter RA. Toxicological principles of metal carcinogenesis with special emphasis on cadmium. Crit Rev Toxicol. 1992; 22(3-4):175-201.

29. Piasek M, Blanusa M, Kostial K, Laskey JW. Placental cadmium and progesterone concentrations in cigarette smokers. Reprod Toxicol. 2001; 15(6):673-81.

30. Hanson ML, Holaskova I, Elliott M, Brundage KM, Schafer R, Barnett JB. Prenatal cadmium exposure alters postnatal immune cell development and function. Toxicol Appl Pharmacol. 2012;261(2):196-203.

31. Israeli E, Agmon-Levin N, Blank M, Shoenfeld Y. Adjuvants and autoimmunity. Lupus. 2009;18(13):1217-25.

32. Seubert A, Monaci E, Pizza M, O'Hagan DT, Wack A. The adjuvants aluminum hydroxide and MF59 induce monocyte and granulocyte chemoattractants and enhance monocyte differentiation toward dendritic cells. J Immunol. 2008;180(8):5402-12.

33. Chelvarajan L, Popa D, Liu Y, Getchell TV, Stromberg AJ, Bondada S. Molecular mechanisms underlying anti-inflammatory phenotype of neonatal splenic macrophages. J Leukoc Biol. 2007;82(2):403-16.

34. Pollard KM, Hultman P, Kono DH. Toxicology of autoimmune diseases. Chem Res Toxicol. 2010;23(3):455-66.

35. Somers EC, Ganser MA, Warren JS, Basu N, Wang L, Zick SM, Park SK. Mercury exposure and antinuclear antibodies among females of reproductive age in the United States: NHANES. Environ Health Perspect. 2015;123(8):792-8.

36. National Research Council (U.S.). Committee on the toxicological effects of methylmercury. In: Toxicological effects of methylmercury. Washington, DC: National Academy Press; 2000.

37. Lee S, Chow CC, Wing YK, Shek CC. Thyroid abnormalities during chronic lithium treatment in Hong Kong Chinese: a controlled study. J Affect Disord. 1992;26(3):173-8

38. Baethge C, Blumentritt H, Berghofer A, Bschor T, Glenn T, Adli M, Schlattmann P, Bauer M, Finke R. Long-term lithium treatment and thyroid antibodies: a controlled study. J Psychiatry Neurosci. 2005;30(6):423-7.

39. Whalley LJ, Roberts DF, Wentzel J, Watson KC. Antinuclear antibodies and histocompatibility antigens in patients on long-term lithium therapy. J Affect Disord. 1981;3(2):123-30.

40. Presley AP, Kahn A, Williamson N. Antinuclear antibodies in patients on lithium carbonate. Br Med J. 1976;2(6030):280-1.

41. Johnstone EC, Whaley K. Antinuclear antibodies in psychiatric illness: their relationship to diagnosis and drug treatment. Br Med J. 1975:2(5973):724-5.

42. Prakken B, Albani S, Martini A. Juvenile idiopathic arthritis. Lancet. 2011; 377(9783):2138-49.

43. Gowdie PJ, Tse SM. Juvenile idiopathic arthritis. Pediatr Clin N Am. 2012; 59(2):301-27.

44. Sepa A, Frodi A, Ludvigsson J. Psychosocial correlates of parenting stress, lack of support and lack of confidence/security. Scand J Psychol. 2004;45(2): 169-79.

\section{Publisher's Note}

Springer Nature remains neutral with regard to jurisdictional claims in published maps and institutional affiliations.

Ready to submit your research? Choose BMC and benefit from:

- fast, convenient online submission

- thorough peer review by experienced researchers in your field

- rapid publication on acceptance

- support for research data, including large and complex data types

- gold Open Access which fosters wider collaboration and increased citations

- maximum visibility for your research: over $100 \mathrm{M}$ website views per year

At BMC, research is always in progress.

Learn more biomedcentral.com/submissions 